\title{
The Use of Multi-Walled Carbon Nanotubes and Titanium Oxide Nano Particles in the Construction of Calcium Ionophore IV Based Calcium-Selective Electrodes
}

\author{
H. Elif Kormalı Ertürün \\ Department of Chemistry, Faculty of Science, Ankara University, Tandoğan 06100, Ankara, TURKEY \\ E-mail: kormali@science.ankara.edu.tr
}

doi: $10.20964 / 2018.10 .58$

Received: 11 June 2018 / Accepted: 8 August 2018 / Published: 1 September 2018

Calcium ionophore IV (ETH 5234) cocktail (CaIC), multi-walled carbon nanotubes (MWCNTs) and titanium(IV) oxide nanoparticles $\left(\mathrm{TiO}_{2} \mathrm{NPs}\right)$ were used to fabricate a new highly sensitive and selective modified glassy carbon electrode (CaIC-MWCNT-TiO $\left.{ }_{2} \mathrm{NP} / \mathrm{GCE}\right)$ for the determination of calcium. The surface of the electrode was characterized by scanning electron microscopy (SEM). The effect of various experimental parameters such as membrane composition, construction technics, $\mathrm{pH}$ on the potentiometric response of the electrode was investigated. The proposed electrode has a linear response in the $1.0 \times 10^{-7}-1.0 \times 10^{-1} \mathrm{M}$ concentration range, with a near-Nernstian slope $(28.5 \pm 0.9$ $\mathrm{mV} / \mathrm{pCa}$ ), and a low detection limit of $6.9 \times 10^{-8} \mathrm{M}$. This electrode was used to the determine calcium content of milk, water and pharmaceutical samples and the results were found to be in good agreement with those obtained by atomic absorption spectrophotometry (AAS).

Keywords: Calcium-selective electrode; ETH 5234 (calcium ionophore IV); Calcium determination; Multi-walled carbon nanotubes; Metal oxide nanoparticles

\section{FULL TEXT}

(C) 2018 The Authors. Published by ESG (www.electrochemsci.org). This article is an open access article distributed under the terms and conditions of the Creative Commons Attribution license (http://creativecommons.org/licenses/by/4.0/). 